\title{
Uterine Adenosarcoma in Obese/Overweight Patients; A Report of Two Cases
}

\author{
Shota Asano ${ }^{1}$, Takashi Shibata ${ }^{1}$, TomokiKodera ${ }^{1}$, Yoshihiro Ikura ${ }^{2 *}$ and Tetsuya Oishi \\ ${ }^{1}$ Department of Obstetrics and Gynecology, Takatsuki General Hospital, Takatsuki 569-1192, Japan \\ ${ }^{2 *}$ Department of Pathology, Takatsuki General Hospital, Takatsuki 569-1192, Japan
}

Received: March 16, 2017; Accepted: March 30, 2017; Published: April 10, 2017

*Corresponding author: Yoshihiro Ikura, Department of Pathology, Takatsuki General Hospital, 1-3-13, Kosobecho, Takatsuki 569-1192, Japan; E-mail: ikura@ajk.takatsuki-hp.or.jp

\section{Abstract}

Uterine adenosarcomas are an uncommon gynecological neoplasm consisting of benign epithelial and malignant mesenchymal components and usually presenting as a polypoid mass. We report herein two cases of uterine adenosarcoma. Both of the patients were obese/overweight (body mass index $32 \mathrm{~kg} / \mathrm{m}^{2}$ and $27 \mathrm{~kg} / \mathrm{m}^{2}$, respectively), and controlling obesity and metabolic disorders seemed to be the key to prevent their post-operative tumor recurrence.

Keywords: Adenosarcoma; Uterus; Oncogenesis; Obesity; Estrogen

\section{Introduction}

Uterine adenosarcomas are a rare gynecological neoplasm consisting of combination of benign glandular epitheliums and malignant mesenchymal cells [1]. From the initial report of Clement and Scullyin 1974, several comprehensive pathologic studies have revealed their pathobiological characteristics in detail; the tumors usually present as a polypoid mass and are frequently misdiagnosed as benign conditions [2,3-7]. However, pathological mechanism of oncogenesis of uterine adenosarcoma is still obscure.

In uterine body malignancies, excess estrogen exposure and obesity are considered potential pathogenic factors. Obese women have an increased risk (approximately 2-3 folds compared with non-obese women) of uterine cancer, which is explained mainly by increase in adipocyte-derived estrogens and insulin resistance [8-10]. In addition, mortality of obese/overweight patients with uterine cancer was about two-fold greater than that of normal body-weight patients (19.1 vs 10.68 per 100,000 patients) [11].

We report herein two obese/overweight patients with uterine adenosarcoma. These cases suggested possible contribution of metabolic disorders to the oncogenic processes.

\section{Case reports}

\section{Case 1}

A 72-year-old obese (body mass index $32 \mathrm{~kg} / \mathrm{m} 2$ ) nulligravida consulted to our hospital because of genital bleeding and lower abdominal pain. She suffered from type 2 diabetes (HbA1c 7.2\%), dyslipidemia, fatty liver and hypertension, and had been treated as an outpatient of the clinic(Figure 1).

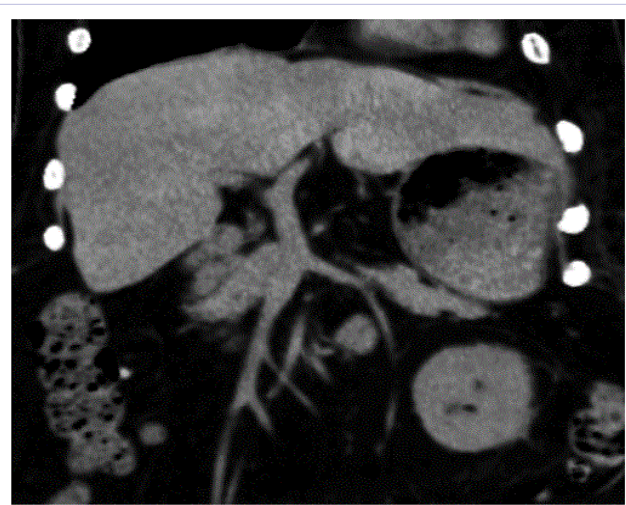

Figure 1: An abdominal computed tomography of Case 1. The liver shows mottled fatty change

Also she had hemiplegia (post-polio syndrome) and severe scoliosis. Gynecological examination revealed a large (ø $100 \mathrm{~mm})$ intravaginal polypoid mass, which was clinically diagnosed as myoma delivery. The lesion was removed by transvaginal resection, and histologically found to be hemorrhagic tumor consisting of fibrous stroma and non-atypical columnar epitheliums (Figure 2).

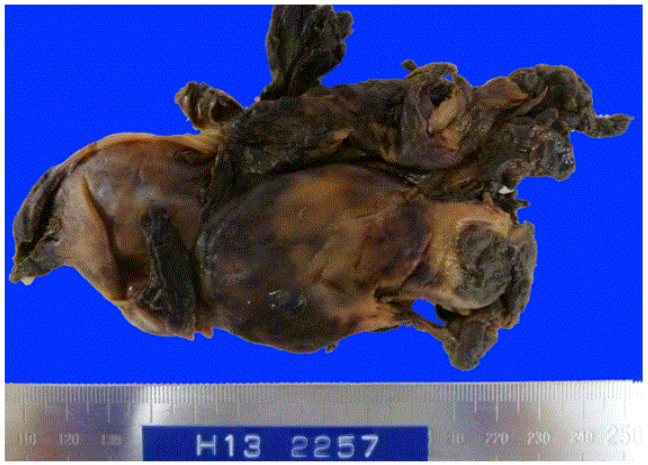

Figure 2: A removed vaginal polypoid lesion of Case 1.

Pathologic diagnosis was difficult and needed several months. The tumor was diagnosed at last as being uterine adenosarcoma, on the basis of characteristic phyllodes-like appearance and repeated recurrences (Figure 3). 


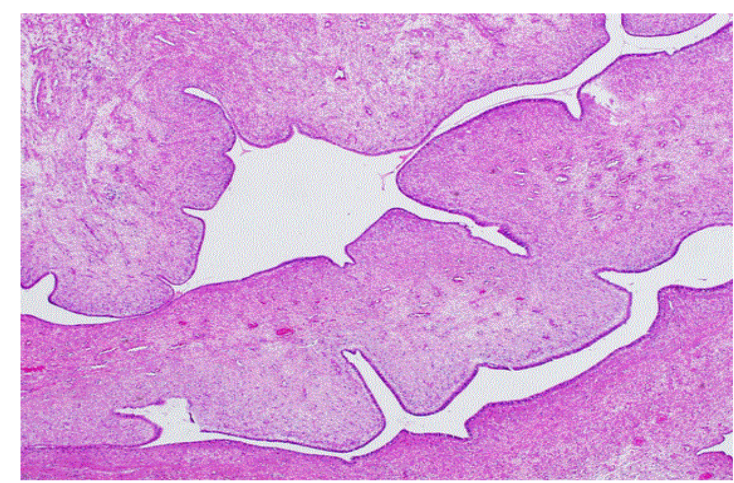

Figure 3: A representative histological finding (phyllodes-like appearance) of the lesion in Case 1. (Hematoxylin-eosin stain, original magnification $\mathrm{x} 100$ )

A total hysterectomy and bilateral salpingo-oophorectomy was performed. Pelvic lymph node dissection was disturbed by pelvic space narrowing related to obesity. A recurrent tumor was found in the specimen, to be present within inner $1 / 2$ layer of myometrium. The final diagnosis was uterine adenosarcoma, FIGO stage Ib (T1b, Nx, M0). She received a strict diet and blood glucose/lipid control, and her body weight has been decreasing. At present (two years after hysterectomy), there is no evidence of recurrence.

\section{Case 2}

A 46-year-old woman (gravid 4, para 2) presented with abnormal genital bleeding and vaginal discomfort. She was overweight (body mass index $27 \mathrm{~kg} / \mathrm{m} 2$ ), but had neither diabetes nor dyslipidemia. A gynecologist found a chicken-egg-sized polypoid mass in her vagina, and excised the lesion. Pathological examination revealed that the polypoid lesion had benign columnar epitheliums but contained atypical mesenchymal cells showing swollen nuclei and frequent mitosis. Typical periglandular cuffing was also seen (Figure 4).

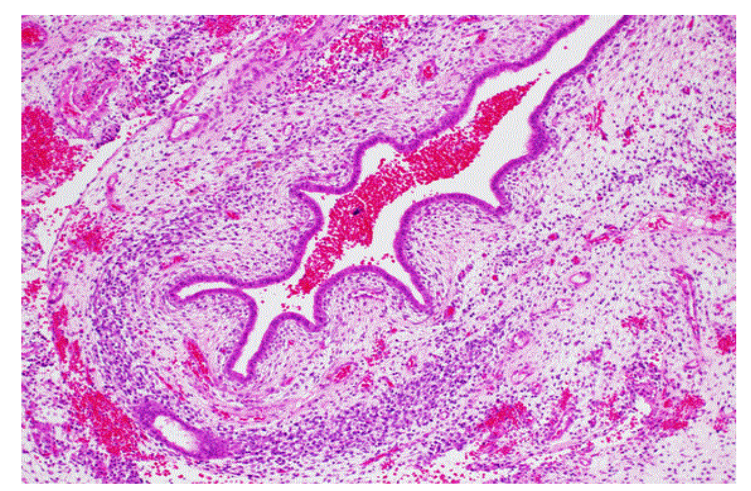

Figure 4: A representative histological finding (periglandular cuffing) of the lesion in Case 2. (Hematoxylin-eosin stain, original magnification $\mathrm{x} 200$ )

The lesion was diagnosed as being uterine adenosarcoma and a total hysterectomy and bilateral salpingo-oophorectomy, and pelvic lymph node dissection was performed. A residual tumor was present within inner $1 / 2$ layer of myometrium. The final diagnosis was uterine adenosarcoma, FIGO stage Ib (T1b, N0, M0). Post-operative course was uneventful, and tumor recurrence has not yet been reported.

\section{Discussion}

It is generally considered that various human malignancies, including gynecological cancers, have close associations with lifestylerelated metabolic disorders, i.e., hyperglycemia, dyslipidemia, hypertension and obesity [12,13]. These metabolic disorders have been suggested to play pathogenic roles in oncogenic processes of the malignant tumors [14]. Endometrial cancer is a representative metabolic disorder-related malignancy, in which excess estrogen production from peripheral adipocytes increasing due to obesity is thought to stimulate endometrial proliferation and oncogenesis [9]. Some investigators insisted on potential contribution of additional mediators (e.g. leptin, insulin resistance, etc.) that link obesity to endometrial cancer [1517]. Certainly, such the common pro-carcinogenic factors related to metabolic disorders may also impact on development of uterine cancers. However, it was confirmed even in their own studies that the obesityestrogen axis was a primary pathway of endometrial carcinogenesis in obese patients $[15,16]$.Obesity and excess estrogen are also recognized to be risks of developing uterine sarcomas [18]. Concerning uterine adenosarcoma, although no obvious association with obesity has been described in an established textbook [1], an American cohort study of uterine adenosarcoma showed a high median body-weight (82 kg), suggesting that obesity/overweight potentially increases its risk [19]. As seen in our Case 1, whose pelvic lymph node dissection was impossible due to obesity, obesity potentially disturbs appropriate treatments for uterine malignancies and consequently worsens patients' prognoses [11]. Management of obesity is considered to be important not only in prevention of uterine adenosarcoma but also in optimization of therapies for it. Also direct suppression of estrogen production may be effective against uterine adenosarcoma. Usefulness of aromatase inhibitors for endometrial stromal sarcoma has already been recognized [20,21]. A recent research suggested that in uterine adenosarcomaonly the sarcoma element but not the glandular element was neoplasm [22]. Accordingly, uterine adenosarcoma can be considered a subtype of endometrial stromal sarcoma, and administration of aromatase inhibitors is expected, not only for endometrial stromal sarcoma but also for uterine adenosarcoma, in both, therapy and prevention [23].

Both of our two patients are obese/overweight individuals and seem to have good application of these treatments as tumor recurrence preventions. Obese patients, especially the elders like Case 1, frequently have other lifestyle-related metabolic disorders. In such cases, aggressive interventions against hyperglycemia and dyslipidemia may suppress general oncogenic processes via insulin-resistance and oxidative stress [14]. In fact, in Case 1 the strict diet and blood glucose/lipid control, which could induce the weight reduction, may have been contributing to prevention of tumor recurrence. Taken together, it should be emphasized that controlling obesity and metabolic disorders is important in prevention of uterine adenosarcoma development and in suppression of its post-operative recurrence. In addition, aromatase inhibitors may become a superior adjuvant therapy for uterine adenosarcomas.

In conclusion, uterine adenosarcomas are rare gynecological malignancies and their oncogenic mechanisms are still obscure. Obesity and excess estrogens are thought to be important risks of uterine adenosarcoma as well as the other uterine body malignancies. Controlling of obesity and interventions to background metabolic disorders are potential therapeutic options for uterine adenosarcomas.

\section{Acknowledgements}

The authors would like to thank Ms Kitaguchi for her excellent assistance in preparation of manuscript. 


\section{References}

1. Zaloudek CJ, Hendrickson MR, Soslow RA. Adenosarcoma. Kurman RJ, Hedrick Elleson L, Ronnett BM, (Eds). Blaustein's Pathology of the Female Genital Tract. 6th ed. 2011;502-506.

2. Clement PB, Scully RE. Müllerianadenosarcoma of the uterus: a clinicopathologic analysis of ten cases of a distinctive type of müllerian mixed tumor. Cancer 1974; 34: 1138-49.

3. Clement PB, Scully RE. Mullerianadenosarcoma of the uterus: a clinicopathologic analysis of 100 cases with a review of the literature. Hum Pathol. 1990;21(4):363-381.

4. Hino A, Hirose T, Seki K, Uehara H, Sano N. Adenosarcoma of the uterine cervix presenting as a cervical polyp.PatholInt. 1998;48(8):649-652.

5. Soslow RA, Ali A, Oliva E. Mullerianadenosarcomas: an immunophenotypic analysis of 35 cases. Am J SurgPathol. 2008;32:1013-1021. doi:10.1097/PAS.0b013e318161d1be

6. Gallardo A, Prat J. Mullerianadenosarcoma: a clinicopathologic and immunohistochemical study of 55 cases challenging the existence of adenofibroma. Am J SurgPathol. 2009;33(2):278-288. doi: 10.1097/ PAS.0b013e318181a80d

7. Pinto A, Howitt B. Uterine Adenosarcoma.Arch Pathol Lab Med. 2016;140(3):286-290. doi: 10.5858/arpa.2014-0523-RS

8. Vainio H, Kaaks R, Bianchini F. Weight control and physical activity in cancer prevention: international evaluation of the evidence. Eur Cancer Prev. 2002;11(Suppl 2): S94-100.

9. Calle EE, Kaaks R. Overweight, obesity and cancer: epidemiological evidence and proposed mechanisms. Nature reviews Cancer. 2004;4:579-591. doi:10.1038/nrc1408

10. vanKruijsdijk RC, van der Wall E, Visseren FL. Obesity and cancer: the role of dysfunctional adipose tissue. Cancer Epidemiol Biomarkers Prev 2009;18(10):2569-2578. doi:10.1158/1055-9965. EPI-09-0372

11.Calle EE, Rodriguez C, Walker-Thurmond K, Thun MJ. Overweight, obesity, and mortality from cancer in a prospectively studied cohort of U.S adults. N Engl J Med. 2003;348:1625-1638.

12.Ikura Y, Tiniakos DG, Tanaka T, Harada K. A case of ruptured hepatocellular carcinoma (HCC) in resolving non-alcoholic steatohepatitis associated with type 2 diabetes: Is early detection of diabetes-related HCC feasible?J Diabetes. 2017;9(3):311-313. doi: 10.1111/1753-0407

13. Ikura Y. Transitions of histopathologic criteria for diagnosis of nonalcoholic fatty liver disease during the last three decades. World J Hepatol. 2014;6(12):894-900. doi:10.4254/wjh.v6.i12.894

14. Kumar V, Abbas AK, Aster JC. Obesity and cancer. In: Pathologic Basis of Disease. 9th ed. 2015;447-448.

15. Dallal CM, Brinton LA, Bauer DC, Buist DS, Cauley JA, Hue TF et al. Obesity-relatedhormones and endometrialcancer among postmenopausalwomen: a nestedcase-controlstudy within the B FIT cohort. EndocrRelatCancer. 2013;20(1): 151-60. doi: 10.1530/ERC12-0229

16. Brinton LA, Trabert B, Anderson GL, Falk RT, Felix AS, Fuhrman BJ, Gass ML, Kuller LH. Serum Estrogens and Estrogen Metabolites and Endometrial Cancer Risk among Postmenopausal Women. CancerEpidemiol Biomarkers Prev. 2016;25(7):1081-1089. doi: 10.1158/1055-9965.EPI-16-0225

17. Lees B, Leath CA. The Impact of Diabetes on Gynecologic Cancer: Current Status and Future Directions.Curr Obstet Gynecol Rep. 2015;4(4):234-249. doi:10.1007/s13669-015-0127-x
18. Schwartz SM, Weiss NS, Daling JR, Gammon MD, Liff JM, Watt J, et al. Exogenous sex hormone use, correlates of endogenous hormone levels, and the incidence of histologic types of sarcoma of the uterus. Cancer. 1996;77(4): 717-724.

19. Carroll A, Ramirez PT, Westin SN, Soliman PT, Munsell MF, Nick AM. Uterineadenosarcoma: an analysis on management, outcomes, and risk factors for recurrence. GynecolOncol. 2014;135(3):455-461. doi: 10.1016/j.ygyno.2014

20. Ryu H, Choi YS, Song IC, Yun HJ, Jo DY, Kim S, et al. Long-term treatment of residual or recurrent low-grade endometrial stromal sarcoma with aromatase inhibitors: A report of two cases and a review of the literature. OncolLett . 2015;10(5):3310 -3314. doi:10.3892/ ol.2015.3674

21. Serkies K, Pawłowska E, Jassem J. Systemictherapy for endometrial stromal sarcomas: current treatment options. GinekolPol. 2016;87: 594-597. doi: 10.5603/GP.2016.0051

22. Piscuoglio S, Burke KA, Ng CK, Papanastasiou AD, Geyer FC, Macedo GS, et al.Uterineadenosarcomas are mesenchymalneoplasms. J Pathol. 2016;238:381-388. doi: 10.1002/path.4675

23. Ioffe YI, Li AJ, Walsh CS, Karlan BY, Leuchter R, Forscher C, Cass I. Hormone receptor expression in uterine sarcomas: prognostic and therapeuticroles. GynecolOncol. 2009;115(3):466-471. doi:10.1016/j. ygyno.2009.08.014 